such as sodium fluoroacetate. The author refers to the saddening feature that the US Fish and Wildlife Service which was almost entirely responsible for the development of the field use of this substance, "has not assumed the remainder of its responsibilities in regard to wildlife".

Finally, as to human hazards, he is not fully convinced that the argument that pesticide residues in food stuffs are insignificant as a health hazard to human beings is well grounded. He agrees that present allowable residues in foodstuffs have not demonstrably caused ill-effects of general distribution. Nevertheless, the hazards from ingestion of residues over very long periods have yet to be assessed. The question whether we have the right to insist on free choice between residue-contaminated and -uncontaminated foods is rightly regarded as a serious moral issue. The current residue legislation in effect says "No!". But it is pointed out that present governmental agencies are not yet able to guarantee continuing conformity to safety standards. The book is primarily, though not entirely, concerned with conditions in the USA, but in one way or another all the problems raised are relevant, and many of them urgent, to Europe as well as to Africa and India. The author has done us all a great service by this work which, it should be added, arises from a study commissioned by the Conservation Foundation.

\title{
African Birds on Record
}

More Voices of African Birds, by M. E. W. North and D. S. McChesney. Houghton Mifflin Co., \$75.00.

This second recording of African birds sponsored by the Laboratory of Ornithology, Cornell University, was well worth waiting for. By relegating explanatory matter to an accompanying leaflet, no fewer than 90 species, as compared with 42 in the earlier record, are given a very fair hearing, and the standard of reproduction shows the marked improvement to be expected. The record strikes a nice balance between the calls of widespread species, which will be highly evocative of Africa to anyone who has stayed anywhere south of the Sahara, and those of local and hence often very shy species, of especial interest to the ardent ornithologist probing "difficult" areas of bush and forest. For the short or long-term resident in Africa, with small or greater passion for birds, the value of these recordings can scarcely be exaggerated. It is not so many years ago that to link some of these splendid sounds with their owners, the doves and cuckoos, owls and nightjars, trogon, thrushes, robin-chats and "cisticola" warblers, in particular, meant patient watching over a period of years. Now it should be possible for anyone to decide at once that the patoh of forest at the bottom of the garden (or near the airport) contains a tambourine dove or bronze-naped pigeon, and to proceed at once to learning more of the life history of such shy species.

The impression given in the leafiet, that many if not most of the species are birds of Kenya and Uganda only, could not be further from the truth. Of the 90 species recorded, half a dozen at most are more or less confined to Kenya and Uganda. Many of the others are far commoner in, and more typical of other parts of the continent. One could also wish that the planning had allowed for closer and more convenient comparison of closely allied songs. Would it be too much to hope that when the series is completed, a new edition will be issued to meet this need?

HUGH F. I. ELLIOTT. 